\title{
Assessing Authentic Representation of Learning Outcomes in Tests of Teacher Education
}

\author{
Nishat Zafar * \\ Sher Zaman ${ }^{* *}$
}

\begin{abstract}
Instructional decisions depend principally on the results of assessment in any of the education systems. But for the purpose, authentic representation i.e., direct alignment between the predetermined learning objectives and assessment tasks of the instructional system is essential. However, the weak linkage of the given two factors in instruction, makes 'validity of results' as well as resultant certification, questionable. The current study was, therefore, conducted to address the issue of alignment in learning objectives and tests, for assessing authentic representation of learning outcomes in tests being used for appraisal of teacher education. The accessible population consists of the tests developed and conducted for assessment of the prospective teachers by the teacher educators of public sector universities. A 'Frame for Assessing Alignment of Tests' (FAAT) was developed for data collection. This frame consists of two sub-frames i.e., FAAT-I, for collecting data from the teacher educators; and FAAT-II, for experts' judgements to determine the level of alignment in learning outcomes and tests tasks. Data were collected on 36 tests, developed by the 18 teacher educators, in the form of teacher educators' perceptions about the linkage and experts' judgement to endorse the educators' reported linkage or otherwise. The results showed that there is a partial evidence of authentic representation of learning outcomes in the tests tasks being used in teacher education programs.
\end{abstract}

Keywords: authentic assessment, learning outcomes, assessment tasks, teacher education programs

\footnotetext{
*Associate Lecturer/PhD scholar, Department of Education, University of Gujrat, Gujrat Email: nishatzeb786@yahoo.com

**Assistant Professor, Department of Education, University of Gujrat, Gujrat

Email: corresponding \& co-author; smzaman@uog.edu.pk
} 


\section{Introduction}

Teacher education in Pakistan had a shift in 2010, from one year B. Ed. programme to 4 years B.Ed. (Hons), to enhance its quality which consequently would improve the learning quality in schools (HEC, 2010). Thus the current B.Ed. (Hons) programme is with extended time duration, well- crafted curriculum having higher and broader learning goals along with longer teaching practice. Accordingly, now almost all the teacher education institutions in Pakistan, are offering B. Ed. (Hons), to achieve a goal of quality teachers: more competent, effective and efficient, for serving the coming generations with quality learning. Thus the trained graduates who have been declared successful after going through the prescribed processes of the reformed teacher education program, and were certified to be professionally qualified teachers. However, different informed stakeholders, raise questions on the subject knowledge as well as teaching skills of currently certified teachers. In this perspective there is need to revisit $\mathrm{B}$. Ed. (Hons) program, particularly its assessment practices which ultimately determine the fate of prospective teachers as well as of their students they teach.

Admittedly, the curriculum of the under consideration program is updated and detailed, for which the Higher Education Commission, Pakistan and USAID's Teacher Education Project engaged the faculty across the country. According to HEC, the syllabi and the course guide have the potential for seismic change through educating our future teachers which ultimately educate next generations (HEC, 2012). Apparently, B.Ed.(Hons) program, having well thought predetermined learning objectives as well as study guides for classroom practices, seems good but in view of the stakeholders' concerns, problem possibly lies in the assessment and consequently certification. Hence analysis of the testing procedures might be helpful for substantiating the given teacher education program.

Assessment works as a mirror in the teaching learning process because determining effectiveness of instructional system depends on assessment results which provides the evidence about the success of an instructional program. For fulfilling the requirements of authenticity, assessment needs to be horizontally (addressing learning outcomes and content coverage) as well as vertically (including higher and lower order thinking levels) sound. Hence selection and preparation of tests tasks to ensure attainability of learning outcomes based education, significantly contributes in the success of 
a teacher education program. Therefore, authentic representation of 'learning outcomes' along with 'content coverage' and addressing the 'higher order thinking', in tests tasks is critical for valid interpretation of the assessment results.

Quality of all the components of pre-service teacher education program is highly required for an effective instructional system. Similarly, Luseno (2001) urges that teacher education programs can only be successful when the outcomes being fostered (assessed) are relevant to prospective teachers' teaching needs. This is because assessment begins with the identification of learning goals and ends with a judgment concerning the extent to which those goals have been achieved (Linn \& Millet, 2000). So the judgments resulting from authentic assessments, might be having valid interpretation of knowledge and skills related learning outcomes. Finally, one can predict prospective teachers' performance, on the basis of the assessment results, if valid, what they can do when they may put forth their best efforts in their profession.

Conclusively the point of reference is the significance of the degree of alignment between learning outcomes of the course and the test tasks, as well as inclusion of higher order thinking and course coverage. But the current assessment practices, even in teacher education programs are not much promising. Hence an empirical study in this regard is conducted to explore whether tests developed by teacher educators are representing the 'program learning outcomes' and ensuring higher order thinking skills given in teacher education courses. It leads, to the large extent, to the degree of authenticity of assessment to predict safely consequence validity of the tests. For this, an enquiry is initiated to probe, 'as whether the graduates who are certified, are legitimate to claim among themselves the abilities/skills which are dressed in the learning outcomes of the program. Hence the researcher felt that problem, if any exists in alignment between intended learning outcomes and assessment tasks.

\section{Related Literature Review}

Following is the brief summary of related literature focusing on teaching learning processes, need and significance of learning outcomes, role of contents and test tasks in teacher education programme.

The importance of aligning in learning outcomes with assessment practices is well articulated in the literature. A curriculum having 
alignment in learning outcomes, teaching learning activities and assessment practices promotes effective instruction within the higher education system (Heron, 2011). Similarly, success of a learning environment is determined by the degree to which there is alignment among all critical factors that create a conducive environment to teaching and learning (Reeves, 2006). The outcomes based instructional approach encourages such educational experiences which are learner-centered and activity based instead of being teacher centered and content based (Awwad, 2010). The same is the requirement, according to Najjar, et al. 2010, that all educational activities along with assessment practices need to be aligned with learning outcomes of the programme.

During instruction, learners can learn in conducive environment enjoying different teaching methods, techniques, learning activities and sharing their ideas with a teacher or peers. While planning as well as conducting such instructional activities, a teacher should have some 'reason' in mind which gives direction all the activities to bring desirable change in behavior through learning particular knowledge or skills. This desirable change or learning needs to squarely relate to the learning outcomes of the programme of instruction. In short all learning process is revolving around learning outcomes (Masters, 2001).

Learning outcome is considered a key concept in the whole scenario of instructional system and education. It is 'a written statement of what the successful student/learner is expected to be able to know or to do at the end of the module/course unit/task' or in other words 'learning outcomes are statements of what a learner is expected to know, understand and/or be able to demonstrate after completion of a process of learning' (Rothman, 2006). He further adds on, outcomes are the qualifications and competences a student is expected to have on completion of learning; however the understandings used when describing learning outcomes varies among the institutions (Rothman, 2006). These variations are in terms of the cognitive levels or different domains of learning outcomes. Here in teacher education at university level, higher order thinking is significant to be addressed in learning outcomes, and in assessment to effectively achieve during the program.

A number of different types of teaching and assessment methods can be used for attaining and assessing learning outcomes, particularly of different levels during instruction. For this, course contents, along with teaching learning strategies, play their instrumental role and coverage of 
the contents across the course is helpful in achieving the learning goals. Although ultimate choice of contents and teaching strategies, both depends on the nature of expected outcomes and the teaching learning process to ensure effective learning. For this the compatibility between types of targets, contents and method is critical, even though the targets may be measured by different assessment tasks. Reality of teaching is that certain methods are more appropriate to some types of targets, which do better than other methods do. The same types of targets can be assessed very well by different assessment practices. This is good for providing more flexibility in the assessment tasks being used, but it also means there is no simple formula or one correct method (Harden, 2002) and for ensuring authenticity, it is necessary to use the systematic and well aligned test procedures in order to ascertain the attainability of objectives of the instructional programme. It is obvious that teachers are responsible for assessing what students in classroom have learned essentially gathering evidence of students learning and using the evidence to document and hopefully, promote students motivation and achievement for their onward professional success. But more than that we instruct, is to follow curriculum; having predetermined objectives, specific related contents and strategies to influence students in a variety of ways, for their effective learning (Hill, 2007).

Assessment has a critical role as Hattie (2003) argues that the assessment data is important when we move away from considering achievement data as saying something about the student, and start considering achievement data as saying something about their teaching. If students do not know something, or cannot process the information, this should be clues for teacher action, particularly teaching in a different way. Similarly, Wiggins \& McTighe (2001) also states that assessment involves 'the determining of the extent to which the curricular goals are being and have been achieved' i.e. summative assessment. Further Black and William (1998a) enunciated the formative role of assessment, which should be used as a source of feedback to improve both teaching and learning. In this way, it is obvious to note that assessment can fulfill a number of purposes in the instructional process. But for playing its legitimate role either in formative or in summative phase, it is desirable for an assessment tool to be both reliable, valid in terms of accuracy of results in line with the specified outcomes and prescribed contents of the programme. 
Having in view the current practices, Boud (2000) held that these in higher education did not equip students for a lifetime of learning and the assessment challenges they would face in the future hence sustainable assessment might be adopted to meet the needs of the day. Burger (2008) concludes that although teachers are aware of the importance of the alignment of teaching, learning and assessment, but they do not understand the assessment standards attached to each learning outcome. About alignment for which Stern and Ahlgrehn (2002) analyzed a range of assessment materials for their alignment and validity according to three distinct criteria: alignment to curriculum goals, testing for understanding and content analysis, which if established, improve the horizontal (range of learning outcomes and course contents) as well as vertical (cognitive levels particularly higher order thinking) alignment of assessment tasks.

Assessment having integral place in curriculum and instruction, needs alignment essentially to the preceding components of instruction. Marca, Redfield, Winter, and Despriet (2000) contended that the alignment process needs to consider the objectives, teaching learning activities and assessment tasks for effective students' learning. The aligned procedures yield accurate and authentic information about student performance and clearly conveys student proficiency as it relates to the content standards, which ultimately enhances the credibility of the instructional process. In view of the above review, researcher theorized and formulated the following research questions to be answered to resolve the issue of quality teachers to be produced by teacher education programs.

i. Do the tests tasks used in B.Ed. (Hons), align with the learning outcomes of the program?

ii. Do the tests tasks ensure coverage of course contents of B.Ed. (Hons) program?

iii. How many of the test tasks address higher order as well as lower order thinking in the B.Ed. (Hons) program?

\section{Methodology}

This is an applied research by purpose, to assess the authenticity of the assessment practices through investigating into the alignment in learning outcomes, cognitive level, content-strands and tests tasks. Further in general it is descriptive study to describe and the alignment of learning outcomes and tests tasks and to summarize the level of alignment. Survey method was used followed by quantitative design, a pre-established one, to collect data based on facts, later to be analyzed in frequencies and percentages. 


\section{Participants}

The target population of the study was all the tests developed by the teacher educators serving in the departments of education of the Public sector universities of Province Punjab in Pakistan. While, accessible population of the study was all the tests (mid and end terms), developed by teacher educators serving in the education departments of those public sector universities which opted revised curriculum 2012, in the Punjab province, Pakistan. At first stage, the ten public universities where departments of education were offering the revised curriculum on teacher education 2012, were selected to be the part of the study. At the second stage, six out of ten universities were selected through convenient sampling technique. The said convenience was in the sense that the selected teachers who had developed sampled tests, assured their cooperation to provide their tests and then to report their understanding and practices in terms of their perceived alignment among the variables being investigated.

From each one of the 06 selected universities, further six paper pencil tests, on each of the three selected core courses (total 36 tests) were included, i.e., i) Teaching Literacy Skills, ii) Teaching of General Science and iii) General Methods of Teaching. These core courses were preferably selected due to their direct relevancy to teaching courses at schools. Further completion of frames for data giving/collection was also demanding thoughtful exercise, sufficient time, hence three core courses were included.

\section{Instrument}

A 'Frame for Assessing Alignment of Tests' (FAAT) was developed for data collection. This frame consists of two sub-frames i.e., FAAT-I, was to be used teacher educators, to report their understanding about possible linkage of the learning outcomes, content strands, and cognitive levels with tests tasks (Appendix-A); and FAAT-II, was to be used by experts for getting their judgements, on the teachers' reported linkage, to determine the level of alignment in learning outcomes, content-strands, cognitive levels and tests tasks (Appendix-B). 


\section{Validation of the Instrument}

The first draft of the frames developed in consultation by the authors, were sent to six experts having subject and testing expertise, to examine their functionality as mentioned in the guidelines of each frame, for collecting quality data. Suggested modifications on the basis of synthesis of the exert opinions, were incorporated in terms of separate list of contentstrands and intended learning outcomes (see page 1 of FAAT-I) and rating of alignment levels was revised from 'strongly aligned', 'fairly aligned' and 'not aligned', to, 'not aligned', 'partially aligned' and 'aligned'. The given suggestions were further helpful in extension of frames for analyzing more aspects of test tasks i.e. content coverage, and cognitive levels as well (see page 1 of FAAT-II).

\section{Data Collection}

Firstly, researcher collected course outlines, mid- \& end-term tests, in total 36. Then listed outcomes and contents were organized on Page-1 of the FAAT-1 by the researcher. FAAT-I having arranged contents and tests tasks were given to the 18 test developers, three from each university, for reporting their intended alignment of the variables. After getting reported alignment of variables on FAAT-I from teacher educators, the researcher rearranged the outcomes, strands and levels in FAAT-II, for experts' judgments to vet the teachers' reported linkage.

At the final step of data collection, the FAAT-II, each one for the three courses, were submitted to the four experts for their judgements about the alignments, to make the reported alignments reliable and valid. Then the completed FAAT-II by the experts, having data in the form of experts' judgements, were analyzed. If three experts' supported the teacher's reported alignment, then it was declared 'aligned', if two of them then 'partially aligned' otherwise, 'not aligned'. Similarly, the alignment of the test task and content-strand was reported, while the cognitive levels were further categorized as 'higher and lower order thinking', for analysis and consequently percentages were used to finally report the identified alignments, and thinking levels of the tests tasks out of the total tasks, which are presented in following results of the study.

The researcher kept in mind following ethical considerations during the data collection process:

i. Got written permission from the sampled administration/teachers 
working in education departments of the sampled universities?

ii. The participants were assured that the collected data would be made unidentified by using codes for names, department, universities etc., and would be used for research purposes only.

iii. After collecting the frameworks by the researcher herself, the researcher assigned serial numbers to the data frames, which were complete in all respect and had the requisite information required for answering the research questions.

\section{Results}

Following are three types of results, against the three research questions, reported here, i.e., i) alignment of tests task with learning outcomes; ii) alignment of tests tasks with content-strands iii) identifying higher and lower order thinking addressed in each test tasks.

\section{Alignment between Test tasks and Intended Learning Outcomes}

The first research question was to assess alignment between test tasks and learning outcomes of three courses, of which analysis and answer is presented in the form of following figures $1(a, b, c)$ with brief description.

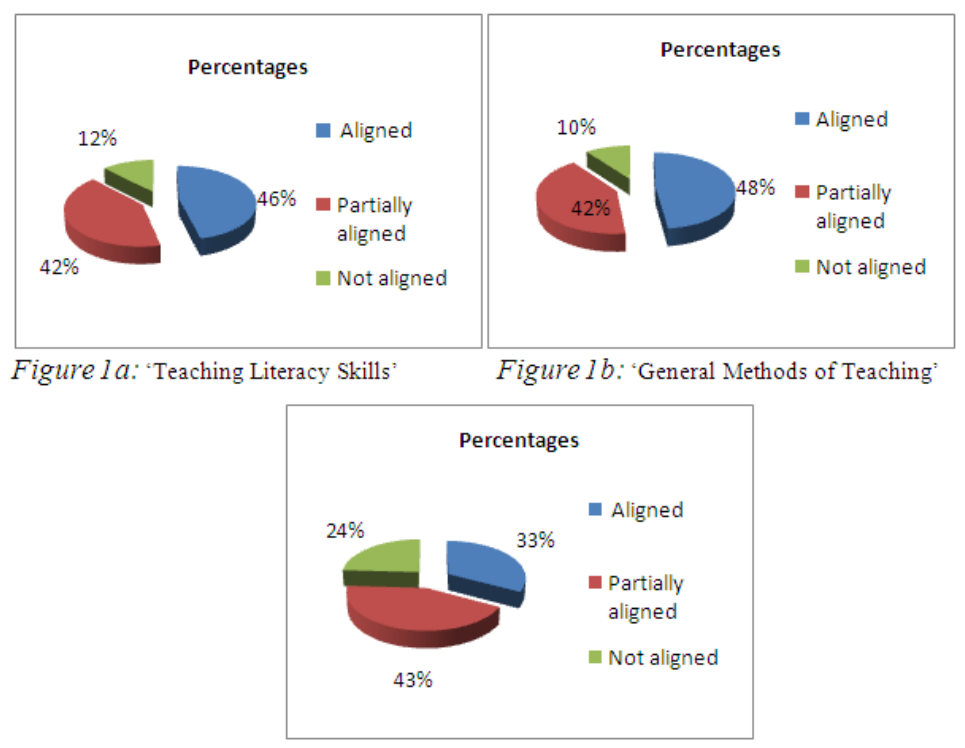

Figure 1c: 'Teaching of General Science' 
Alignment of test tasks with learning outcomes of 'Teaching Literacy Skills' course (Figure $1 a$ ) shows that $46 \%$ test tasks are aligned with the course prescribed learning outcomes, $42 \%$ are partially aligned while $12 \%$ test tasks are not aligned with LOs of the teaching literacy course being offered in teacher education B.Ed. (Hons) programme.

Alignment of test tasks with learning outcomes of 'General Methods of Teaching'(Figure $1 b$ ) shows that $48 \%$ test tasks are aligned with the said course learning outcomes, $42 \%$ are partially aligned while $10 \%$ test tasks are not aligned with the learning outcomes.

Alignment of test tasks with learning outcomes of 'Teaching of General Science' (Figure 1c) judged by the experts is that,33\% test tasks are aligned with the said course learning outcomes, $43 \%$ are partially aligned while $24 \%$ are not aligned with the course's LOs.

The reported results for determining the alignment of the test tasks with the LOs of the selected three courses reflected that the tests in i.e. 'Teaching Literacy Skills', 'General Methods of Teaching' were better aligned with learning outcomes as compared to the alignment results of tests tasks on ' Teaching of General Science'. There were approximately $12 \%, 10 \%$ and $24 \%$ of tasks of the paper-pencil tests which did not assess those abilities that are meant to be developed among the prospective teachers and mentioned in the form of course objectives or learning outcomes

\section{Alignment between Test Tasks and Content strands}

Alignment between test tasks and content-strands of three courses is presented in the form of following figures $2(a, b, c)$ with brief description. 


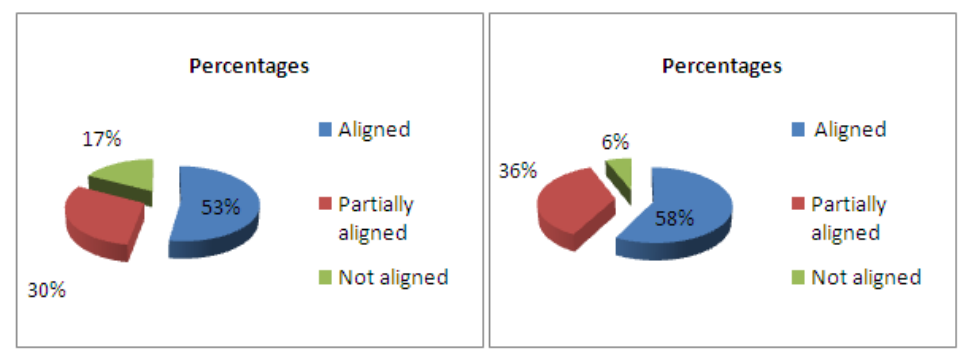

Figure 2a: 'Teaching Literacy Skills' Figure 2b: 'General Methods of Teaching'

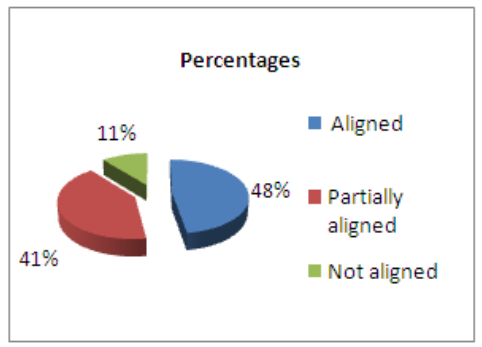

Figure 2c: "Teaching of General Science'

Alignment of test tasks with content strands (Figure 2a) shows that $53 \%$ of the test tasks in the subject of "Teaching Literacy Skills" are aligned with content strands, $30 \%$ are partially aligned while $17 \%$ test tasks are not aligned with the content strands of teaching literacy skills course taught and test by teacher educators to prospective teacher graduates.

Alignment of test tasks with content strands (Figure $2 b$ ) shows that $58 \%$ of the test tasks in the course of "General Methods" of Teaching are aligned with content topic, $36 \%$ are partially aligned while $6 \%$ are not aligned with the content strands of general methods of teaching course being offered in B.Ed. (Hons) programme.

Alignment of test tasks with content strands of teaching of general science (Figure $2 c$ ) shows that there are $48 \%$ of the test tasks in the subject which are aligned with its contents, $41 \%$ of them are partially aligned while $11 \%$ are not aligned with the course content strands.

The results given in the above figures $2(a, b, c)$ showed that the most of test tasks were aligned with the content strands in all three courses. Whereas, $17 \%, 6 \%$ and $11 \%$ test tasks of the selected courses were not 
aligned with the content strands of the three sampled courses respectively. In this case, if the students got scores on almost 11 percent of those tasks which were not aligned with the content strands than the question on the validity of the given assessment tasks of the test arises. Although, the teacher educators had been provided with the course guides on these courses having rich and thoughtfully organized material regarding content strands. Hence the reasons needed to be sought as why the teacher educators could not develop properly aligned test tasks with the content strands and test tasks.

\section{Assessing Higher Order as well as Lower Order Thinking}

Each learning outcomes reflects that it has focus on which cognitive level of students thinking. An analysis about the higher and lower thinking order being assessed of the prospective teachers from different universities is presented in the following table.

Table 1

\begin{tabular}{llccc}
\hline Courses & Analysis & $\begin{array}{c}\text { Higher Order } \\
\text { Thinking }\end{array}$ & $\begin{array}{c}\text { Lower Order } \\
\text { Thinking }\end{array}$ & Total \\
\hline $\begin{array}{l}\text { Teaching Literacy } \\
\text { Skills }\end{array}$ & N=814 & 0 & 814 & 814 \\
& Percentage & $0 \%$ & $100 \%$ & 100.0 \\
$\begin{array}{l}\text { General Methods } \\
\text { of Teaching }\end{array}$ & $\mathrm{N}=836$ & 100 & 736 & 836 \\
& Percentage & $12 \%$ & $88 \%$ & 100.0 \\
$\begin{array}{l}\text { Teaching of } \\
\text { General Science }\end{array}$ & N=956 & 20 & 936 & 956 \\
& Percentages & $2.1 \%$ & $97.9 \%$ & 100.0 \\
\hline
\end{tabular}

Firstly, table 1 shows that all the test tasks on the course 'Teaching Literacy Skills' are measuring only lower order thinking among the prospective teachers who are actually getting higher education which is bound to provide them with higher order thinking skills. Hence, there was no test item reported by the teacher educators and the experts assessing higher order thinking of the said course.

Secondly, the table shows the analysis of the test tasks on the course of 'General Methods of Teaching'. There are 12\% of the higher order thinking testing tasks and $88 \%$ of the tasks are assessing lower order thinking among the prospective teachers in the said course of B. Ed. (Hons) programme. 
Thirdly, table 1.1 shows results of the test tasks on the course of 'Teaching of General Science'. There are $2.1 \%$ of the test tasks measuring higher order thinking while $97.9 \%$ of the tasks are assessing lower order thinking among the prospective teachers.

It is evidenced from the table 1.1, that average less than 5\% test tasks of the selected three courses were there, which have the ability to assess higher order thinking among the prospective teachers being certified as graduates of teacher education programme in Pakistan. The situation was worse in the selected courses because most of the test tasks of the said courses were assessing only lower order thinking abilities (i.e. remembering, understanding and applying) and ignoring the analytical and creative abilities among the future teachers which is alarming for quality education at schools in Pakistan. Although the nature of the courses and the learning outcomes are inclusive of higher order thinking i.e. analyzing, evaluating and creating etc. The course demands and the future jobs demands do not seem matching to the levels of learning among the prospective job seekers in school education. The results are alarming and awakening in the context of prospective teachers' 'quality status' because their certification is questionable in terms of alignment in general, and content representation and coverage of higher cognitive abilities in particular.

\section{Discussion}

The background, nature and implications of the results, with support of the findings of the similar other studies, are discussed in the following. The observed alignment in test tasks and content strands were almost 50\%. It means half of the test tasks were aligned while a sound numbers of test tasks are partially aligned with the learning outcomes and the content strands. Thus the tasks functioning and their prediction which are even partially aligned reported is also questionable. Thus the representation of the contents in tests of the selected courses reflected that almost 50\% validity and authenticity of the tests existed in prevailing assessment practices in B.Ed. (Hons) program.

The study results further revealed that the learning outcomes were not fully addressed through tests in the teacher education courses because half of the test tasks were partially or not aligned with LOs. Hence it is difficult to declare that achievement of the learning outcomes of the courses being taught, is ensured. The LOs based on higher order thinking are the 
compulsory part of graduate trained teachers but the study results reflected that higher order abilities were not addressed in the tests tasks in B.Ed. (Hons) program. It is, therefore, on the basis of finding concluded that the certification of prospective teachers is least valid in terms of less authentic representation of higher order thinking abilities which are essential requirements for performing complex instructional tasks during practical teaching by the teachers. The reported concern is also described by Edstrom (2008) that "course evaluation should be regarded as a component of constructive alignment, together with the learning outcomes, learning activities and assessment”.

Higher order thinking is the critical requirement to be developed among the teacher educators, which was very rarely addressed in the test tasks included for assessment in B.Ed. (Hons) Program. It is therefore concluded that the test tasks were not balanced in terms of the higher and lower order thinking, tested in the given paper- pencil tests. Overall, the analysis of the test documents revealed that the assessment practices of B.Ed. (Hons) were weak for confidently predicting the intellectual development of the prospective teachers who were pass outs of the teacher education programme. Such anomalies have been reported by Naomi and Tithe (2013) who examined the reflection of Bloom's Taxonomy on the learning outcomes of secondary social science curriculum of Bangladesh. The study found uneven application of the Bloom's classification of objectives and poor reflection of Bloom's Taxonomy on learning outcomes of the curriculum.

The perceived implications behind the identified least alignment, although the curriculum of B.Ed. (Hons) was carefully developed by the experts in a continuous dialogue ensuring linkage between different elements of the curriculum, test development procedures particularly using table of test specifications were not properly applied for developing content wise comprehensive and objectives wise valid tests. The content strands in the investigated assessment tasks were not fully inclusive, which make content coverage poor. Furthermore, the implications of the findings on the partial or no alignment of the LOs are serious as reported by Shiekh et al. (2013) who conducted a qualitative study to explore the gap between learning outcomes and the assessment instruments in the universities and their affiliated colleges in the Punjab province. They also pointed to the lack of alignment between the course objectives and the formal assessment practices used at the end of the semester in formative assessment. This also reflects the lack in understanding the significance, skills and implementation of 
test development procedures for developing and conducting good assessment tasks in the prevailing instructional system.

The investigated and reported assessment scenario demands that it is necessary to provide such type of rigorous professional trainings to teacher educators, in the area of testing and evaluation so to enable them to develop valid tests having authentic representation of the predetermined leaning outcomes. It may be realized through continuous training of the teacher educators to make them able to construct test tasks based on the higher order thinking as well. Thus a balance in thinking order particularly inclusion of the higher order thinking in testing, which is missing, is inevitable for authentic assessment particularly for teacher education programs which are the incubators of future teachers who are most significant factor for quality teaching and learning at schools. The increased number of test tasks on lower order thinking would probably be due to multiple choice questions hence the teacher educators need training in developing MCQs addressing the higher order or the extended response test tasks which may be the part of assessment tasks then it would be possible to address and assess higher order thinking. Further, a study is recommended to find out the alignment of the quizzes, presentations and assignments with the learning outcomes of the courses being offered in teacher education programs. 


\section{References}

Awwad, M. (2010). Outcome-Based Education at Philadelphia University. A paper presented at the National Conference for the Development of Study Plans, Teaching, and Scientific Research, Amman, Jordan.

Black, P. \&William, D. (1998a). Assessment and Classroom Learning. Assessment in Education, 1(5), 7-74.118.

Boud, D. (2000). Sustainable assessment: rethinking assessment for the learning society, Studies in Continuing Education, 22(2), 151-167.

Burger, M. (2008). The Alignment of Teaching Learning and Assessment in English Home Language in Grade 10 in District 9, Johannesburg. Johannesburg: University of South Africa.

Cohen, L.,Manion, L.,\& Morrison, K. (2000). Research methods in education, ( $5^{\text {th }}$ ed.). London: Routledge.

Edström, K. (2008). Doing course evaluation as if learning matters most; .Higher Education Research \& Development, 27(2), 95-106.

Harden, R.M. (2002). Learning outcomes and instructional objectives: is there a difference? Medical Teacher,24(2), 151-155.

Harden, R.M. (2007b). Outcome-based education - the ostrich, the peacock and the beaver. Medical Teacher,29, 666-671.

Hattie, J. (2003). Teachers make a difference: What is the research evidence? Teacher quality: What does the research tell us? 19-21 October, 2003, Melbourne.

Heron, D. (2011). Constructive Alignment: A Desirable and Achievable Aspiration in Geological Field Teaching. University of London, Surrey, U.K.

Higher Education Commission, (2010) curriculum on Education, B.S. Education, HEC, Islamabad.

Higher Education Commission, (2012) curriculum on Education, BEd (Hons) Elementary, HEC, Islamabad.

Hill, A. (2007). Continuous curriculum assessment and improvement: a case study. New Directions for Teaching and Learning 112, 33-46.

Marca, L. Redfield, D. Winter, P. \& Despriet, L. (2000). State standards and state assessment systems: A guide to alignment. Series on standards and assessment. Washington, DC: Council of Chief State Offices. 
Luseno, F. K. (2001). An assessment of the perceptions of secondary special and general education teachers working in inclusive settings in the common wealth of Virginia. Unpublished Ph.D. dissertation: Faculty of the Virginia Polytechnic Institute and State University.

Linn, R. \& Miller, (2000). Measurement and Assessment in Teaching $\left(9^{\text {th }}\right.$ ed.). India: Dorling Kindersley, Pearson Education.

Masters, G. N. (2001). Standards and assessment for students and teachers: A developmental paradigm. In Zbar, V. \& MacKay, T. (ed.) Leading the Education Debate. Melbourne: ACER Press.

Mietlicki, S. (2004). Preparing pre-service teachers for diversity issues in the classroom. Improving teacher quality: Proceedings of the 2004 teacher quality enhancement project, Arizona State University.

Najjar, J. et al. (2010). Aligning assessment with learning outcomes in outcome - based education. Madrid: Telematica University.

Naomee, I. \& Tithi, U. (2013). Reflection of bloom's taxonomy in the learning outcomes of secondary social science curriculum of bangladesh. International Journal of Science and Research, 2(2), 16-27.

Reeves, T. (2006). How Do You Know they are Learning? The Importance of Higher Education. International Journal of Learning Technology, 2(4), 55-71.

Rothman, R. (2006). (In) Formative assessments: New test and activities can help guide student learning. Harvard Education Letter, (22), 6.

Sheikh M.\& et al. (2013). A comparative study of the assessment practices and proposed curriculum objectives in revised teacher education programs. Bulletin of Education and Research, 35(2), 51-72.

Stern, L. \& Ahlgren, A. (2002). Analysis of students' assessments in middle school curriculum materials: Aiming precisely at benchmarks and standards. Journal of Research in Science Education, 39, 889-910.

Wiggins, G. \& McTighe, J. (2001). Understanding by Design (2 $2^{\text {nd }} e d$.). Alexandria, VA: Association for Supervision and Curriculum Development.

\section{Citation of this Article:}

Zafar, N., \& Zaman, S. (2018). Assessing authentic representation of learning outcomes in tests of teacher education. Pakistan Journal of Education, 35 (3), 19-38. 


\section{Annexure "A" \\ Framework for Assessing Alignment of Tasks (FAAT-I) \\ (For Teachers)}

Guidelines: There is a list on page " 1 " of the intended learning outcomes (ILOs) each one has different identity number, and similarly "contentstrands' of the course outlines for B.Ed (Hons) semester fall- 2013. There is also a complete list of 'your test tasks' on page\# $2 \& 3$ (specimen of both are given in the following tables).

Table 2

Specimen from List of Page 1

Intended Learning Outcomes ILOs and Content-strands from Course Outlines of Mid Term and End term assessments on Teaching Literacy for B. Ed. (Hons), during Semester Fall-2013

\begin{tabular}{|c|c|c|c|}
\hline $\begin{array}{l}\text { ILO } \\
\text { No }\end{array}$ & $\begin{array}{l}\text { List of Intended Learning Outcomes } \\
\text { (ILOs) }\end{array}$ & $\begin{array}{l}\text { Topic } \\
\text { No }\end{array}$ & $\begin{array}{l}\text { List of } \\
\text { content } \\
\text { strands }\end{array}$ \\
\hline 1.1 & $\begin{array}{l}\text { Articulate the characteristics of skilled } \\
\text { readers and writers and the many } \\
\text { purposes of reading and writing in } \\
\text { everyday and professional life. }\end{array}$ & 2.1 & $\begin{array}{l}\text { What is } \\
\text { reading }\end{array}$ \\
\hline 1.2 & $\begin{array}{l}\text { Provide a working definition authentic } \\
\text { reading and writing as a meaning/based } \\
\text { process. }\end{array}$ & 2.2 & $\begin{array}{l}\text { What is } \\
\text { writing }\end{array}$ \\
\hline 1.3 & $\begin{array}{l}\text { Describe the role oral language place in } \\
\text { reading and writing development. }\end{array}$ & 2.3 & $\begin{array}{l}\text { Components } \\
\text { of reading }\end{array}$ \\
\hline
\end{tabular}

You are kindly requested to review each one task of your tests (midterm and end-term) given on page $2 \& 3$, to put the serial/identity number of related ILO from page\#1 (which you intended to assess by this certain task) on the given space under test task, as well you are required to put the serial/identity number of related content-strands from page\#1 (for which you have developed and added this task) in the given space under the task. Further please tick in the following table, an abbreviated letter; $R=$ Remembering $\mathrm{U}=$ Understanding $\mathrm{Ap}=$ Application, $\mathrm{An}=$ Analyzing $\mathrm{E}=$ Evaluating $\mathrm{C}=$ Creating, for showing the cognitive level you intended to measure by this task 


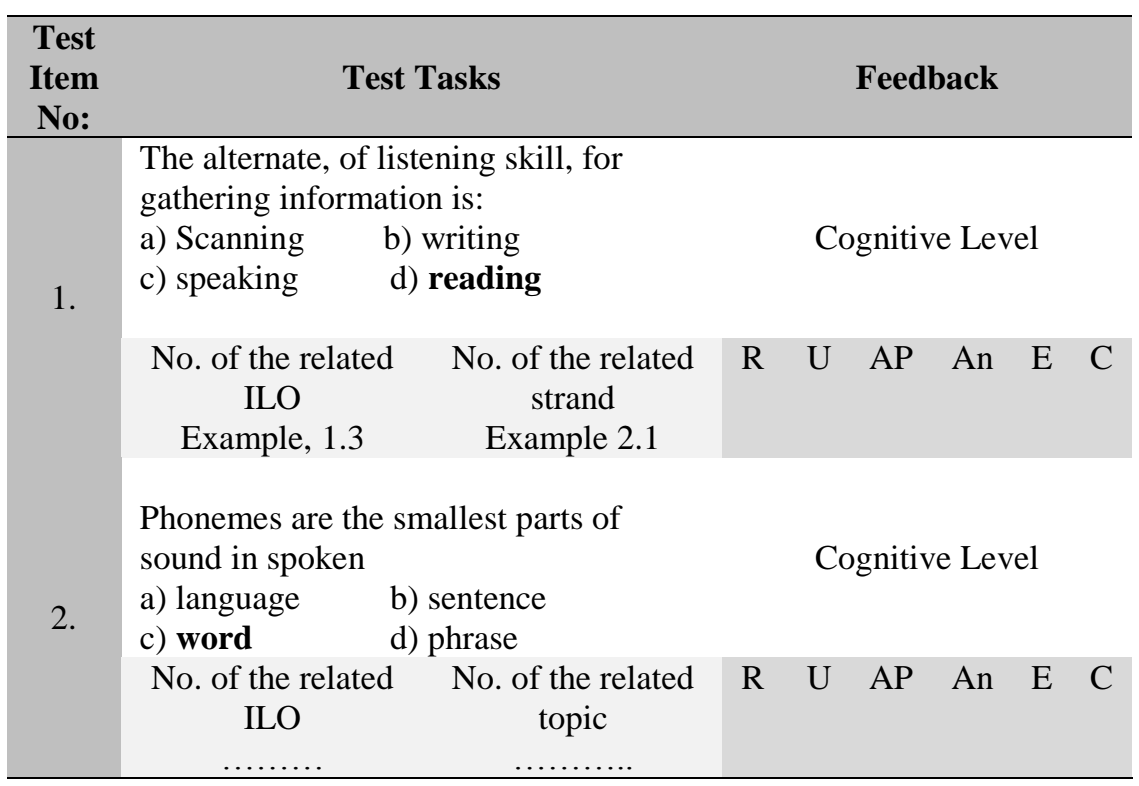




\section{Annexure "B" \\ Framework for Assessing Alignment of Tasks (FAAT-II) (For Experts)}

Guidelines: There is a list of intended learning outcomes (ILOs) and list of topics from the course out line of " ' for Bed (Hons.) during Semester Fall-2013 on separate pages. On the given course outline, in column-1, there is complete test tasks given by the course teacher. Column-2 \&3 have the concerned teachers' reported alignment $b / w$ 'test item \& topic', and 'test item \& ILO'. Column-4 has the teacher's reported cognitive level of each test item. All these 4 columns provide base for expert judgments in next columns.

You are kindly requested to review:

i. Columns $1 \& 2$ and put your expert judgment under ${ }^{1}$ Alignment $b / w$ test item \& topic in the given column.

ii. Columns $1 \& 3$ and put your expert judgment under ${ }^{2}$ Alignment $b / w$ test item \& ILO in the given column.

iii. Columns $1 \& 4$ and put your expert judgment under ${ }^{3}$ Alignment $b / w$ the identified cognitive level \&test item in the last column.

Your judgment may be under any one of the following three categories:

1. Not Aligned (NA)

2. Partially Aligned (PA)

3. Aligned (A)

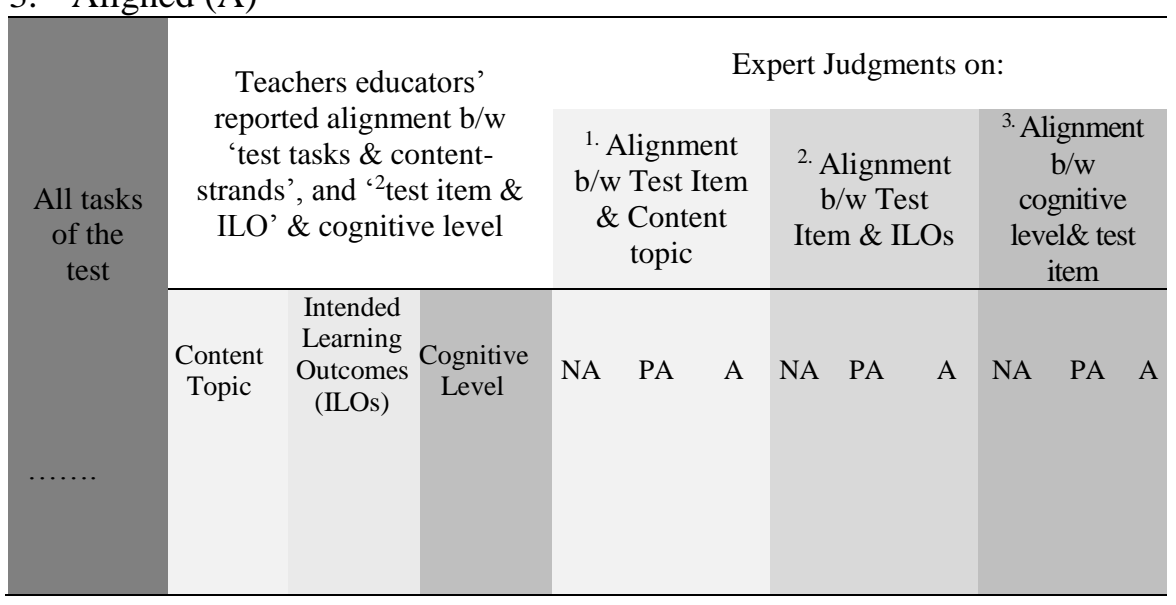

